\title{
A policy for the size of individual unemployment accounts
}

\author{
Rubén Castro $^{1^{*}}$ (D), Michael Weber ${ }^{2}$ and Gonzalo Reyes $^{2}$
}

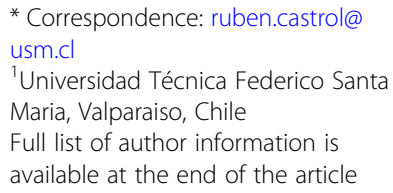

* Correspondence: ruben.castrol@ usm.cl

${ }^{1}$ Universidad Técnica Federico Santa Maria, Valparaiso, Chile Full list of author information is available at the end of the article

\begin{abstract}
Individual unemployment accounts (IUAs) attenuate the moral hazard attached to unemployment insurance. However, the available literature provides no policy recommendation about what percentage of the contributions should go to IUAs. We propose criteria of actuarial neutrality and use a simple job search model to argue that a sizable proportion of the contributions could go to IUAs without changing benefits and contribution rates, and therefore not negatively affecting well-being. We derive this result from a model, first, and then use simulations to show that it also holds in more realistic settings and different labor market dynamics.

JEL Classification: J64, J65, H21

Keywords: Social security, Unemployment insurance, Unemployment accounts, Moral hazard
\end{abstract}

\section{Introduction}

The main role for unemployment insurance (UI) is to attenuate liquidity constraints, a market failure that plays against some individuals; while many individuals can save and borrow to smooth their consumption, some cannot when facing unemployment shocks. Holmlund (2015) and Kyyrä et al. (2017) provide a detailed discussion, including the motivation for state rather than private provision of UI.

However, UI introduces by itself a market failure called moral hazard: the unemployed do not take into account the alternative use of the resources when deciding on their labor behavior. Basically, the UI acts as a subsidy for the price of leisure and is distortionary, making unemployment more prevalent than it should be. Most of the numerous empirical literature finds support for the existence of moral hazard attached to UI; a detailed review can be found in Schmieder and Von Wachter (2016). Indeed, most UI systems include several mechanisms to fight moral hazard: a maximum length of unemployment benefits, shrinking the benefit rate as the unemployment spell gets longer, and requiring proof of job search, among others.

In this context, a new mechanism to fight moral hazard emerged around the year 1990: the introduction of a self-insurance component, by means of individual unemployment accounts (IUAs). In this mixed system, an X\% of contributions goes to the workers' IUA, which pays for his/her unemployment benefits, until either they are exhausted (and the risk-pooling component starts to pay the benefits) or the worker finds a job. Any

(c) The Author(s). 2018 Open Access This article is distributed under the terms of the Creative Commons Attribution 4.0 International License (http://creativecommons.org/licenses/by/4.0/), which permits unrestricted use, distribution, and reproduction in any medium, provided you give appropriate credit to the original author(s) and the source, provide a link to the Creative Commons license, and indicate if changes were made. 
remaining funds from IUAs are withdrawn at retirement or before. The key idea here is that workers experience less moral hazard during the self-financing stage of their unemployment spells while all the consumption smoothing properties are preserved.

This setting has been attracting the attention of developing countries; many are introducing their first UIs, amidst the particularities of their labor markets and institutions (Vodopivec 2013; Robalino and Weber 2013), and the mixed system is already present in Argentina, Austria, Brazil, Chile, Colombia, Ecuador, Jordan, Mauritius, Panama, and Peru. ${ }^{1}$

Now, policy makers need to set the size of the IA component in their UI systems, but from the academic literature, it is not clear what the right size of the IA component is. This study is the first to propose a right size.

Feldstein and Altman (1998), "the" foundational article for IUAs, perform a simulation based on data from the USA; they conclude that, under different simple scenarios for the impact in moral hazard, UI-associated taxes could be mostly transformed into IUAs. And some articles discuss a wide range of topics related to UI and IUAs in developing countries (notably Robalino et al. 2009, Vodopivec 2013, and Sehnbruch and Carranza 2015). But none of those authors propose a size recommendation for policy makers.

Theoretical models of well-being, based on economic behavioral models applied to mixed systems (Orszag and Snower 2002, Bovenberg and Sørensen 2004, and Jongen 2009 are the available ones), provide a framework to set a value for the optimal $X$; however, as is also the case for risk-pooling UIs, this theoretic analysis is still somewhat far from policy recommendations about the parameters of the system. Indeed, current UI policy decisions are based mostly on standards and best practices.

A key advancement in the literature is the optimal benefit formula proposed by Chetty (2006), stemming from the work of Baily (1978), who proposed a reduced-form expression for the optimal benefit level based on observable elasticities (rather than a deep primitives).

In this study, we explore a different question: what percentage of the contributions should be redirected to UIAs? One possible answer could be explored by adding this "percentage of the contribution" into the social planner's objective function in Chetty (2006). In this study, we also focus on a practical answer but we follow an actuarial perspective rather than an economic one. IUAs introduce an actuarial relief in the system because lower moral hazard implies lower spending in benefits but also introduce actuarial pressure because the new benefit (the withdrawals of funds from IUAs) implies higher spending. Our contribution is that $X$, the percentage of contributions to be derived from IUAs, could be set at the maximum value such that the actuarial impact from introducing IUAs is zero. Up to this actuarially neutral level of $X$, there are no well-being drawbacks, since contribution and benefit rules can stay the same, but beyond it, either a higher contribution rate (i.e., disincentive to formalize, naïve distortions of private savings, lower net salaries) and/or lower level of benefits or coverage (i.e., less protection) is necessary. In the following example, a risk-pooling UI has an actuarially neutral $X$ of $23 \%$ (Fig. 1).

We explore a standard job search model and found a simple conceptual formula for the actuarially neutral $X$ and then use simulations to add more realistic properties (like risk-heterogeneity across wage levels). We focus on job creation moral hazard, leaving job termination moral hazard for future research ${ }^{2}$; job creation/termination stands here for all the dynamics underlying the beginning/ending of job relationships.

The only empirical evidence regarding the moral hazard effect of a mixed system is Reyes et al.'s (2011) comparison of aggregated labor market behavior of IUA-financed 


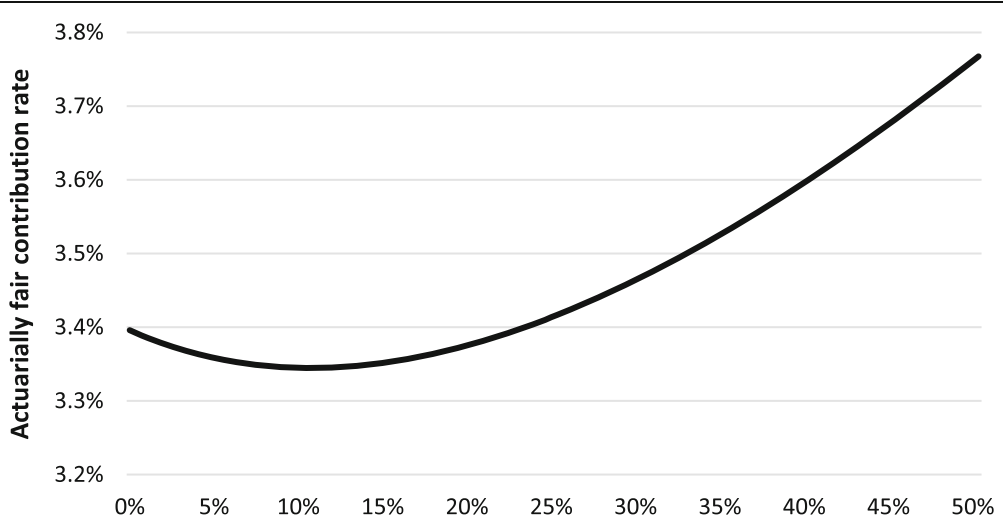

$\mathrm{X}: \%$ of the contributions that enter the Individual account

Fig. 1 Actuarially fair contribution rate by $X$ (example). Source: author's calculation

versus non IUA-financed unemployed individuals in Chile. Nagler (2013) found employment duration effects from the introduction of the UI systems in Chile, although it is not clear what is the pooling-versus-mixed component of this effect. For our study, we take a conservative position, assuming that UIs' moral hazard is low (setting a -0.3 "job creation elasticity with respect to UI benefits"), which we discuss after presenting the model.

Section 2 covers the methodology and summarizes the model that is detailed in the Appendix; Section 3 shows the results and Section 4 discusses the findings.

\section{Methodology}

We first discuss the model and then the simulations.

Define the actuarially fair contribution rate as the one equating expected contributions with expected spending in a stationary setting. Define $X$ as the percentage of the actuarially fair contribution rate that goes to IUAs. The objective of our methodology is to determine the "actuarially neutral $X$," i.e., the $X$ where the introduction of IUAs (in an otherwise pure risk-pooling system) has no actuarial impact on the system.

\subsection{The model}

The model is based on a standard setup (see a complete review on Rogerson et al. 2005): workers contribute an actuarially fair rate $c$ of their wages to UIs and randomly terminate their labor relationships at a job termination rate that for simplicity is set fixed at $\lambda$. The actuarially fair level of $c$ is defined as the level where the expected inflow equals the expected outflow of cash into the system. In the case of unemployment, workers receive a replacement rate of $b$ of their previous wage, without time limit, until they start a new labor relationship, which depends on receiving a job-wage offer whose present value is superior to the present value of not accepting it. From there, a job creation rate emerges. This rate can be further explored on the grounds of the individual's search effort and, relatedly, at the rate of arrival and distribution of job-wage offers. These parameters can be further extended to add worker-firm matching and bargaining, all common elements in this literature. For the purposes of this study, however, it suffices to summarize the job creation behavior in two single parameters: $\alpha$, the job 
creation rate before the introduction of IUAs, and $F$, the proportional increase in $\alpha$ during the self-financeable stage of the unemployment spell. $F$ captures the effect of IUAs on moral hazard. We assume no behavioral impact of IUAs outside the self-financeable stage of the unemployment spell. Administration costs are not included in the model.

In the pure risk-pooling UI system, the actuarial balance can be summarized as the difference between total contributions and total benefits, i.e., as the difference between total employed $(E)$ times the contribution rate and total unemployed $(U)$ times the average benefit. Under the actuarially fair contribution rate $(c)$, the balance is zero:

$$
\text { Actuarial balance }=0=E c-U b=E\left[c-\lambda d_{u} b\right] \Rightarrow c=\lambda d_{u} b
$$

where the average wage is set to $1, d_{u}$ is the average duration of an unemployment spell $\left(d_{u}\right.$ $=1 / \alpha$ ), and $U$ can be replaced with $E^{*} \lambda{ }^{*} d_{u}$ if the system is stationary (see Rogerson et al. 2005, page $966^{3}$ ). Thus, $c$ is the actuarially fair contribution rate equals the expected flow of new unemployment spells per worker $(\lambda)$ times the expected total cost per unemployment spell $\left(d_{u}^{*} b\right)$.

Since $\lambda$ is exogenous, and we want to keep $c$ constant, any actuarially neutral change must keep the same expected total cost per unemployment spell. Therefore, we focus on that expected cost.

Then, IUAs are introduced. In our theoretical model, for simplicity, funds can be withdrawn from the IUAs if the unemployment spell does not exhaust the account, while the more realistic setting of deferring any withdrawal until retirement is explored using simulations. We model the expected total cost of an employment spell as a function of $X$ ( $X$ is the percentage of the actuarially fair contribution rate that goes to IUAs). We first obtain an expression for an unemployment spell whose previous job duration was $d_{e}$, and then, we integrate it over the stationary distribution of $d_{e}$; these two steps are used because the initial size of an IA is determined by $d_{e}$. We assume that the job termination and the job creation rates are not a function of time spent either employed or unemployed. We simplify the model by assuming that during the self-financeable stage of any unemployment spell, the job creation rate will be $F$ times greater than the situation without IUAs. The expected actuarial balance of any given unemployment spell as function of $X$ is (see details in the Appendix):

$$
\text { Actuarial balance }=X \frac{\lambda}{c}\left[\frac{F-1}{(1+F)\left(\frac{\mathrm{c} * X}{\lambda * \mathrm{~b} * d_{u}}\right)+1}-1\right]
$$

Underlying Eq. 2, there are two opposite actuarial components: on one hand, unemployment spells are shorter and therefore cheaper, but on the other hand, a new benefit is added (the withdrawals from IUAs), making them more expensive. By the nature of the problem, as $X$ grows, the second effect starts to dominate over the first one.

So we set $X$ such that the larger parenthesis in Eq. 2 is zero, and then, we replace $c$ $=\lambda^{*} d_{u}^{*} b$ from Eq. 1, to arrive at the central finding of the model:

$$
\text { Actuarially neutral } X=\left[\frac{F}{1+F}\right]
$$

The actuarially neutral size of IUAs depends only on $F$, the percentage increase in the job finding rate during the self-financeable stage of the unemployment spell. It is not a 
function of job creation or termination rates, and therefore, it is not a function of average duration of employment or unemployment, nor is it a function of the level of benefits, and therefore, it is not a function of the risk-pooling UI actuarially fair contribution rate. Simply, if $F$ lays between 20 and 40\%, the actuarially neutral $X$ lays between 17 and $29 \%$. If $F$ goes to infinity, i.e., everybody finds a job immediately after losing a job, the actuarially neutral $X$ is $100 \%$.

Figure 1 shows the case of $F=30 \%$.

It is important to mention that even relatively large changes in the "job-finding behavior" will have little impact on the employment rate, because the unemployed are a minority; from there, the growth in total contributions associated with the introduction of UIAs could be extremely small. In our modeling for simplicity, we assume that total contributions stay the same regardless of $X$, and, along the same lines, our simulations show that they stay very constant, indeed.

\subsection{Simulations}

In order to explore the actuarial balance in more realistic settings (maximum duration of benefits at 6 months, maximum and minimum level of benefits, involuntary/voluntary job termination ratio, withdrawals of funds from the IUAs only at retirement, and job termination rates that change as the employment spell progress), we code a simulation of a stable group of 5000 individuals. We assume that the job creation rate is constant across the UI covered stage. ${ }^{4}$ We add a $5 \%$ monthly change in the job termination rate (as the employment spell progresses, following one of the few international articles in this topic: Hobijn and Sahin 2007, which includes developed countries only, though). We assign lifetime wages randomly from the observed wage distribution in the formal labor market of Indonesia (taken from the Indonesian Labor Market Survey, Sakernas). As the maximum and minimum level of benefits, we use the value of the sixth and first decile of income, without attaching behavioral changes to them. We do not try a decaying rate of benefits because the empirical literature gives them a small role in labor behavior.

The simulations start with a risk-pooling UI system and everyone with an employed status. The simulation loop is applied until it reaches its stationary level. This level is reached at about 300 months (25 years) after the introduction of IUAs. The same seed was used for all the trajectories of random numbers. We report the actuarial balance, which is the average difference between the inflow rate per worker (namely the contribution rate) and the average outflow per worker (total benefits and withdrawals from IUAs, over total wages).

For the following results, $d_{u}$ is set to 6 months and the duration of employment (the inverse of $\lambda$ ) is set to 60 months. A sensitivity analysis covers other values.

\section{Results}

If $X$ is set at $0 \%$, then the UI system is a pure risk-pooling one. At this starting point, the simulated population shows an employment rate of about $91 \%$ and an actuarially fair contribution rate of about $3.4 \%$. If $X$ is set higher than 0, i.e., if IUAs are introduced, the actuarially fair rate changes. That change depends on $F$, the percentage increase in the job finding rate during the self-financeable stage of the unemployment spell. Figure 2 shows the actuarially fair rate as a function of $X$, under five different values of $F$, from very low (0\%, where IUAs have no effect on moral hazard) to extremely high $(100 \%$, where during 


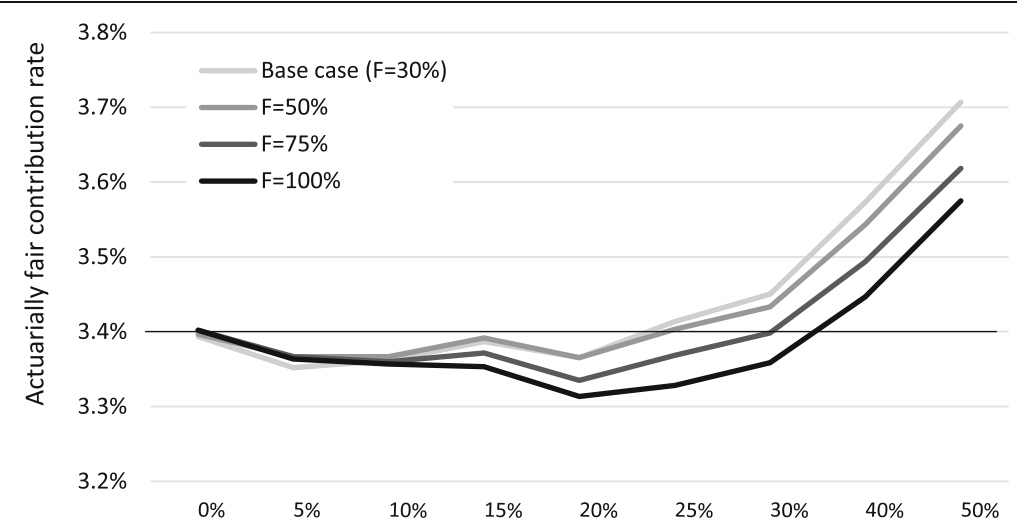

$\mathrm{X}: \%$ of the contribution rate that enters the Individual account

Fig. 2 Simulated actuarially fair contribution rate by $X$ (the percentage of the contributions that goes to IUAs) and $F$ (the percentage increase in the job finding rate during the self-financeable stage of the unemployment spell). Source: author's calculation, using a simulated population. The pure risk-pooling average duration of unemployment is set to 6 months, whereas the average duration of employment is set to 60 months. The replacement rate is set at $50 \%$

the self-financeable period the job creation rate doubles the one in a purely risk-pooling setting).

Figure 2 shows that the predictions from the simple model, regarding the actuarially neutral $X$, holds well in more realistic settings. If $F$ is $30 \%$, for example, the actuarially neutral $X$ is approximately $23 \%$. Figure 2 shows the same inverted $U$ shape as Fig. 1, because at low levels of $X$, the positive impact (less moral hazard, i.e., more job creation) is greater than the negative impact (withdrawals of money from the IUAs), but at higher levels of $X$, the opposite is true.

In Fig. 2, it is possible to see the direct implication from Eq. 3: the higher the $F$, the higher the actuarially neutral $X$, i.e., the higher the impact of IUAs on moral hazard, the higher the amount that can be directed to them without causing an actuarial imbalance in the system. Regarding an empirical value for $F$, the literature does not have a clear estimation of elasticities of unemployment duration to UIAs' benefits, but the more "classical" case of elasticities of unemployment duration to UI benefits lie in the [0.3-1] range (Kyyrä et al. 2017; Schmieder and Von Wachter 2016). For our study, under any discounting of future benefits, $F$ should be smaller than the elasticity to UI benefit cuts; as a "base case" scenario, $F=0.3$ could be sufficiently lower than the elasticity to UI benefit cuts, which as a base case could lie around 0.7 . With $F=30 \%$, then, even at $X=40 \%$, the actuarial imbalance will be low: $0.15 \%$ of wages.

It is interesting to note that heterogeneity in labor risk rates could have a low impact on the finances of the UIA system, because workers of high performance (low risk of job destruction and high risk of job creation) will be at the same time more costly (because they withdraw larger amounts from their UIAs) and less costly (because the higher the UIAS, the lower the moral hazard and so the lower the spending in unemployment benefits) than workers of low performance. From there, an association between wages and performance will also have a low impact on the finances of the systems, to the extent that benefits are indexed to wages. We replicated the calculus behind Fig. 2 but assuming a linear relation between wages and hazard rates such that higher wage quintile has about 2.5 (0.5) times the employment (unemployment) duration of lower wages, and results are closely the same. 
We also replicated the calculus behind Fig. 2 but assuming that withdrawals of funds from the IUAs have to wait until retirement, instead of occurring right after the end of each unemployment spell (as the model assumes). Results barely change. As withdrawals are referred until retirement, (A) more of the UI benefits are paid out of IUAs and less out of the risk-pooling component, but those effects counteract each other almost perfectly, and (B) while withdrawals are lower, the influence of lower moral hazard is longer, so IUAs are increased and then withdrawals increase; those effects counteract each other almost perfectly.

The actuarially neutral $X$ in the pure model, shown in Eq. 3, is not a function of the unemployment rate. Figure 3 shows that also in the more realistic setting of the simulation, the unemployment rate has a small role as determinant of the actuarially neutral $X$, as both higher and lower unemployment rates reach the same results as Fig. 2. It is worth noting that in this model, IUAs influence the behavior only of the unemployed, who are a relative minority of the population. ${ }^{5}$ As stated earlier, the empirical evidence of risk-pooling UI influence on the employed is limited, and there is no evidence regarding the "IUAs versus pure risk-pooling" effect.

\section{Conclusions}

As unemployment insurance (UI) systems slowly spread throughout the developing world, the issue of moral hazard gains attention and so does one relatively new mechanism to fight it: individual unemployment accounts (IUAs). The available literature, however, provides no policy recommendation about what percentage of the contributions should go to IUAs. We propose here an "actuarially neutral" rule and use a simple job search model to argue that even if the "lower moral hazard" effect of IUAs is low, even a sizable UIA component (like $40 \%$ of the contributions, for example) will fight moral hazard while preserving the original contributions and benefit rates. This result

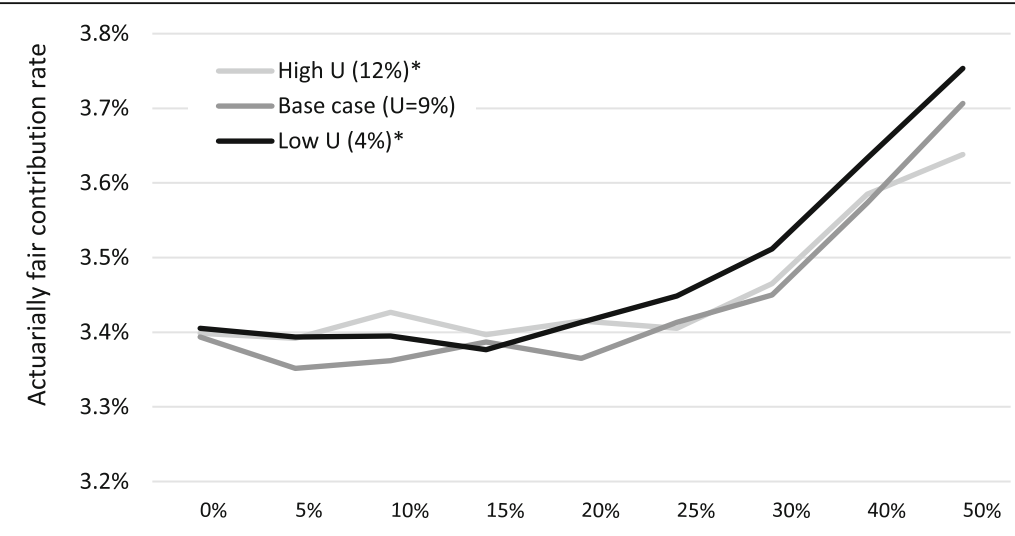

$X: \%$ of the contribution rate that enters the Individual account

Fig. 3 Simulated actuarially fair contribution rate by $X$ and unemployment level. Source: author's calculation, using a simulated population. The asterisk indicates the replacement rate is set at $50 \%$ in the base case and is set at a higher/lower value in the lower/higher unemployment scenario to facilitate the graphical comparison (by keeping the risk-pooling actuarially fair contribution at 3.4). The unemployment level refers to the one before introducing the individual accounts. The pure risk-pooling average duration of unemployment/employment is set to $6 / 60$ months. $F$, the percentage increase in the job finding rate during the self-financeable stage of the unemployment spell, is set at $30 \%$ 
holds under our simplified model, although we use simulations to add more realistic assumptions.

It is interesting to note that heterogeneity in labor risk rates could have a low impact on the finances of the UIA system, because workers of high performance will be at the same time more costly (greater withdrawals from UIAs) and less costly (less UI benefits). From there, an association between wages and performance will also have a low impact on the finances of the systems, to the extent that benefits are indexed to wages.

Our model assumes early withdrawals of funds while the common rule of at-retirement withdrawals is explored by simulations (most authors, like Feldstein and Altman 1998 and Stiglitz and Yun 2002 analyze withdrawals at retirement, although some countries allow early withdrawals). The actuarially fair contribution rate of those two options appeared as basically the same. Therefore, if it happens that early withdrawals have a greater "low moral hazard" effect, then this policy could be a better alternative than previously thought (in our modeling, early and at-retirement configurations have the same effect on moral hazard).

Our study has some important limitations that are left for future research. First, there is almost no evidence regarding the impact of UIAs on behavior. In our base case scenario, we assume the impact is half of the impact of UI on behavior, for which there is much available literature, but future empirical research could focus on the distinctive impact of UIA and UI systems. Also, we assume independence between the size of the UAIs (the percentage of the contributions that go into IUAs) and the level of benefits, but the social planner objective function should jointly include both the level of benefits and the size of UIAs. Chetty's (2006) optimal benefit formula, for example, suggests that larger sizes (and thus lower moral hazard) are associated with greater benefits. Moreover, we do not add heterogeneity, other than random components in the model and simulations. We also focus solely on job creation moral hazard.

\section{Endnotes}

${ }^{1}$ Chile introduced in the year 2002 the first mixed system in the world (Acevedo et al. 2006, describe the introduction process). Ferrer and Riddell (2009) describe outcomes from mixed systems across Latin American countries.

${ }^{2}$ The evidence regarding risk-pooling UI's effect on job termination is rather limited (Tatsiramos and van Ours 2012) but points to the existence of such effects.

${ }^{3}$ Take Equation 25 on Rogerson et al. (2005) and express the rates as the inverse of the average durations.

${ }^{4}$ The literature discusses two effects of UI exhaustion which has two components (Schmieder et al. 2012, 2016; Card et al. 2007): (A) leaving the unemployment state to the employment state, where a small spike is found, and (B) leaving the UI administrative records without moving to the employment state, where a big spike is found. Therefore, the actual job creation rate (the risk of leaving unemployment towards employment) could be more or less constant during the UI-covered stage.

${ }^{5}$ Without IUAs in the model, unemployment is about $9 \%$ and, in the highest IA case, with $X=100 \%$, is about $6 \%$ (setting $F$ at $30 \%$ ). 


\section{Appendix}

We derive first the expression for the expected actuarial balance among unemployment spells of workers with $d_{e}$ previous job duration. Assume by now that the previous job's wage is "1," and let $M$ represent the length of the self-financeable period $\left(M=\mathrm{c}^{*} \mathrm{~d}_{\mathrm{e}} / \mathrm{b}\right.$, i.e., total funds in the IA divided by the benefit rate, assuming no interest). It is possible to classify these unemployment spells in three groups, depending on their duration of unemployment $\left(d_{u}\right)$ :

A. Those where $d_{u}$ was lower than $M$ before the introduction of IUAs. Since the IUAs' incentive favors working, their new $d_{u}$ will be counterfactually even lower. Now, even if their new unemployment duration is zero, the actuarial impact is negative here, since these workers used to be "givers" and now they keep all their contributions to their IUAs, regardless of their new duration of unemployment.

B. Those whose $d_{u}$ was and counterfactually still is higher than $M$. The average $d_{u}$ conditional on $d_{u}>M$ does not change with the introduction of IUAs, if we assume no "scaring" effect on job search, i.e., that even though the worker spent some time under the IA incentive, after passing $M$ he/she went back to his/her typical behavior just as if he/she were never under any incentive. With the no scaring assumption, the actuarial impact here is zero.

C. Those whose $d_{u}$ was higher than $M$ before the introduction of IUAs but is counterfactually lower afterwards. All the distance from their old $d_{u}$ and $M$ represent a positive actuarial balance, since no incentive is paid, while the distance between their new $d_{u}$ and $M$ is neutral since one dollar of savings here just increases the incentive payment by one dollar. So, the expected actuarial balance from these unemployment spells is positive.

The relative size of group A (where the actuarial balance is negative) and group C (where it is positive) determines the expected actuarial balance from introducing IUAs. For ease of exposition, we compute here the expected actuarial balance directly as the old minus new expected spending in an unemployment spell:

$$
\text { Actuarial balance }_{d_{e}}=\underbrace{b \widetilde{d_{u}}}_{\begin{array}{c}
\text { Old average } \\
\text { spending }
\end{array}}-\left[\frac{c d_{e}(P)+b \widetilde{d_{u>M}}(1-P)}{\begin{array}{c}
\text { New average } \\
\text { spending }
\end{array}}\right]
$$

where $\widetilde{d_{u}}$ is the average duration of unemployment before the introduction of IUAs, $P$ is the expected proportion of unemployment spells that are lower than $M$ after the introduction of IUAs, and $\widetilde{d_{u>M}}$ is the average duration of unemployment conditional on being higher than $M$ (note that this conditional duration does not change after the introduction of IUAs, given the no scaring assumption). From Eq. 4 plus the assumption of constant hazard rate model for the job finding rate after $M$, (that turns $\widetilde{d_{u>M}}$ into $\left.\widetilde{d_{u}}+\mathrm{M}\right)$ the net saving became:

$$
\text { Actuarial balance }_{d_{e}}=b\left(P \widetilde{d_{u}}-M\right)
$$

Now, we extend our results to any unemployment spell. Here, we integrate Eq. 5 over the distribution of $d_{e}$ to obtain an expression for the ENS of one random unemployment 
spell in the stationary population of unemployment spells. As $d_{e}$ grows, $P$ decreases and $M$ increases, so the actuarial balance for its associated unemployment spells decrease and eventually became negative. We integrate Eq. 5 over the stationary distribution of $d_{e}$, assuming a constant hazard model for the job termination rate, arriving at:

$$
\text { Actuarial balance }=\int_{0}^{\infty} b(\underbrace{\left(1-e^{-\left(\frac{f}{d_{u}}\right)\left(\frac{c t}{b}\right)}\right)}_{P} \widetilde{d}_{u}-\underbrace{\frac{c \cdot t}{b}}_{M}) \frac{1}{\widetilde{d}_{e}} e^{-\frac{1}{d_{e}} t} d t
$$

where the term to the right of the larger parenthesis is the probability density function for the distribution of $d_{e}$ under a constant hazard model with parameter $1 / \widetilde{d}_{e}$. In Eq. 6, we also assume that the job creation before $M$ is constant, and we also assume it is greater than the one before introducing IUAs by a constant factor, $F$, so $P$, the probability of not surviving until time $M$, formally $\left(1-e^{- \text {constant hazard rate } M}\right)$, became the expression in the inner parenthesis of Eq. 6,.

After some algebra, Eq. 6 leads to Eq. 3 in the main body of the manuscript. To simplify notation, the main text uses $d_{u}$ to refer to the average $d_{u}$.

\section{Acknowledgements}

The authors thank Truman Packard and Milan Vodopivec for many useful discussions and Juan Tapia for revising the final version. The authors would also like to thank the anonymous referee and the editor for the useful remarks. Responsible editor: Denis Fougère

Availability of data and materials

The survey data in the manuscript comes from a public source.

Competing interests

The IZA Journal of Labor Policy is committed to the IZA Guiding Principles of Research Integrity. The authors declare that they have observed these principles.

\section{Publisher's Note}

Springer Nature remains neutral with regard to jurisdictional claims in published maps and institutional affiliations.

Author details

${ }^{1}$ Universidad Técnica Federico Santa Maria, Valparaiso, Chile. ${ }^{2}$ World Bank, Washington, D.C., USA.

Received: 6 March 2018 Accepted: 22 August 2018

Published online: 06 September 2018

\section{References}

Acevedo, G., Eskenazi, P., Pagés, C. Unemployment insurance in Chile: a new model of income support for unemployed workers. Social Protection Discussion Papers, World Bank, No 0612. 2006

Baily M (1978) Some aspects of optimal unemployment insurance. J Public Econ 10:379-402

Bovenberg AL, Sørensen PB (2004) Improving the equity-efficiency trade-off: mandatory savings accounts for social insurance. Int Tax Public Financ 11:507-529

Card D, Chetty R, Weber A (2007) The spike at benefit exhaustion: leaving the unemployment system or starting a new job? Am Econ Rev 97:113-118

Chetty R (2006) A general formula for the optimal level of social insurance. J Public Econ 90(2006):1879-1901

Feldstein, Martin, Daniel Altman. Unemployment insurance savings accounts. NBER Working Paper No. 6860, 1998

Ferrer, Ana M. and W. Craig Riddell. Unemployment insurance savings accounts in Latin America: overview and assessment. SP discussion paper 910. 2009

Hobijn, Bart and Aysegül Sahin. Job-finding and separation rates in the OECD. Staff Report no. 298. 2007

Holmlund B (2015) Theoretical aspects of unemployment insurance. Policy report. Uppsala: Department of Economics, Uppsala University

Jongen, Egbert. An analysis of individual accounts for the unemployment risk in the Netherlands. CPB Document No 186. 2009

Kyyrä, Tomi, Hanna Pesola, Aarne Rissanen. Unemployment insurance in Finland a review of recent changes and empirical evidence on behavioral responses. VATT Research Reports 184. 2017

Nagler P (2013) How unemployment insurance savings accounts affect employment duration: evidence from Chile. IZA J Labor Dev 2:9 
Orszag, M., Dennis Snower. From unemployment benefits to unemployment accounts. IZA DP No. 532. 2002

Reyes G, van Ours JC, Vodopivec M (2011) Incentive effects of unemployment insurance savings accounts: evidence from Chile. Labour Econ 18(6):798-809

Robalino DA, Weber M (2013) Designing unemployment benefits in middle and low income countries: beyond risk-pooling vs. savings. IZA J Labor Policy 2(12):1-18

Robalino, David, Vodopivec, Mílan, Bodor A.Savings for unemployment in good or bad times: options for developing countries. IZA Discussion Paper No. 4516. 2009

Rogerson R, Shimer R, Wright R (2005) Search-theoretic models of the labor market: a survey. J Econ Lit XLIII:959-988

Schmieder J, Von Wachter F, Bender S (2012) The effects of extended unemployment insurance over the business cycle: evidence from regression discontinuity estimates over 20 years. Q J Econ 127(2):701-752

Schmieder J, Von Wachter F, Bender S (2016) The effect of unemployment benefits and nonemployment durations on wages. Am Econ Rev 106(3):739-777

Schmieder JF, von Wachter T (2016) The effects of unemployment insurance benefits: new evidence and interpretation. Annu Rev Econ 8:547-581

Sehnbruch, Kirsten, Rafael Carranza. Unemployment insurance based on individual savings accounts: lessons for other Latin American and developing countries from Chile. SDT 401. 2015

Stiglitz, Joseph E. and Jungyoll Yun. Integration of unemployment insurance with retirement insurance. NBER Working Paper No. 9199,2002

Tatsiramos, Konstantinos and Jan C. van Ours. Labor market effects of unemployment insurance design. IZA DP No. 6950. 2012

Vodopivec M (2013) Introducing unemployment insurance to developing countries. IZA J Labor Policy 2:1 Page 8 of 23

\section{Submit your manuscript to a SpringerOpen ${ }^{\circ}$} journal and benefit from:

- Convenient online submission

- Rigorous peer review

- Open access: articles freely available online

High visibility within the field

- Retaining the copyright to your article

Submit your next manuscript at $\boldsymbol{\nabla}$ springeropen.com 